\title{
SOME INDIVIDUAL AND SOCIAL FACTORS IN VENEREAL DISEASE*
}

\author{
BY \\ ROBERT SUTHERLAND
}

\author{
Medical Adviser and Secretary of the Central Council for Health Education
}

\section{Incidence of Venereal Disease}

In $1946,72,249$ new cases of venereal disease in England and Wales were dealt with at venereal disease clinics (Report of the Ministry of Health, 1947). This, however, is almost certainly an understatement of the incidence. In the first place, the figures reported show a striking difference between the ratio of gonorrhœa to syphilis in females on the one hand, and of gonorrhœa to syphilis in males on the other. If the ratio of gonorrhœa to syphilis in males $(2 \cdot 6: 1)$ is applied to females, the figure is increased to 88,369 . It is true that the figures in the official report will include some who were registered at two or more clinics ; but they do not of course include those patients who were treated privately. On the showing of the official figures alone, therefore, it is probably safe to say that there were at least 90,000 new cases of venereal disease in 1946.

In the second place there is evidence that this ratio of 2.6 cases of gonorrhœa to 1 of syphilis may itself be an under-estimate. It has been found on Tyneside (Macfarlane, 1948), for example, that the ratio is $3.5: 1$. If this ratio is in fact applicable to the country as a whole, the number of new cases of venereal disease in 1946. would be raised to not far short of 110,000 .

Moreover, it would be ingenuous to imagine that this figure includes all hew cases of venereal disease in England and Wales in 1946. As many as two out of every three contacts traced have been found to be infected (Macfarlane, 1948). Contact tracing is, however, notoriously unsuccessful. Even in the same clinic the percentage of cases in which the sexual contact is successfully traced may vary from as high as $\mathbf{9 3 . 2}$ per cent. where the contact was husband or wife to as low as 20 per cent. where the contact was not the marriage partner (Brown

\footnotetext{
* An Address delivered to the Medical Society for the Study of Venereal Diseases, Feb. 25, 1949.
}

and Nichols, 1948). Many cases of venereal disease must, therefore, be both unknown and untreated.

So we must turn to routine blood tests of pregnant women and blood donors to seek some indication of the incidence of syphilis amongst the adult population. On Tyneside (Macfarlane, 1948) a routine examination of the blood of 40,000 pregnant women and 50,000 blood donors showed that 0.9 per cent. had syphilis; and, of almost 3,000 women attending Doncaster ante-natal clinics between November 1943 and 1947 whose blood was examined routinely for syphilis, practically the same percentage $(0.87)$ was found to be infected (Galloway, 1949). If, to be on the safe side, we apply the ratio of 2.6 cases of gonorrhœa to every 1 of syphilis, we can assume that at least 3.5 per cent. of the adult population of England and Wales has or has had venereal disease ; that is roughly one out of every 29 adults. If the ratio $3 \cdot 5: 1$ is applied, these figures become 4.4 per cent. and roughly one in 23.

It is interesting to compare the figures for England and Wales with the reported findings in the United States. In Philadelphia it is estimated that the venereal disease rate in the adult population is between 4 and 5 per cent. (Ingraham and Burke, 1948). And the examination of $15,000,000$ selected service registrants showed that 2 per cent. of the whites had venereal disease of some kind at the actual time of physical examination (Greve, 1946).

These figures are not so much worse than our own that they can justify any feeling of moral superiority or make American experience and findings inapplicable to England and Wales.

\section{Incidence of Promiscuity}

Since venereal disease is a by-product of promiscuity, these statistics give some indication not only of the size of the problem that we are facing, but also of the extent to which our accepted code of sexual behaviour is being broken. Unfortunately, I have 
not yet seen recorded any investigation that clearly establishes the proportion of sexual intercourse that on an average transmits venereal disease. There is little doubt, however, that the infection is passed on in only a minority of pre-marital sexual liaisons. To what extent, then, is pre-marital sexual intercourse taking place? If we add illegitimate live births, legitimate live births within eight months of marriage, and pre-maritally conceived still births and abortions, there are probably 95,000 to 100,000 pre-marital conceptions each year (Stocks, 1944). But not all pre-marital intercourse results in conception. Indeed, in the case of women at their most fertile period, living in conditions most likely to favour conception (married women aged 20 to 24 without any gynæcological troubles, living with their first husbands and not practising contraception), there are on an average only 8.9 conceptions for every 100 presumptive ovulations (Pearl, 1939) ; that is, only one in eleven ovulations results in pregnancy. It has been found, too, that the median frequency of coitus per month in married couples in the age group 20 to 29 is 9 (Pearl, 1939). If these two findings are related, it appears that on an average only one in ninety-nine acts of sexual intercourse results in pregnancy in the most fertile group even where no contraceptive is used. In these days when knowledge concerning contraception is so common, however, it is surely only the most irresponsible of unmarried couples who would have as many as 100 acts of intercourse without any attempt at contraception. The figure of 100,000 pre-marital conceptions must, therefore, be almost entirely the fruit of the careless rapture of early unions or of later unions where attempts at contraception were unsuccessful. It seems, therefore, that we can safely multiply the figure of 100,000 pre-marital conceptions many times in order to get some indication of the number of people indulging in pre-marital intercourse.

When we search for other evidence of the extent of promiscuity, we find from an investigation of a representative group of English working-class people, that pre-marital intercourse was admitted by half the married men investigated and by almost a quarter of the married women (Woodside, 1946).

From America comes the Kinsey Report which, although it has surprised and shocked many people, appears to be based upon a thorough and skilled investigation by individual interview of over 5,000 American men of all social classes and from all States. In round figures, three-quarters admitted having had pre-marital intercourse during their late teens and one-third of the married men admitted extra-marital intercourse. For unmarried men under the age of 20 the average number of orgasms with the discharge of semen was three and a half per week, two of which took place as a result of masturbation, and one and one-third as a result of pre-marital intercourse (Kinsey and others, 1948).

It is necessary to be cautious about these figures : they relate to Americans and not to Englishmen; and they were obtained by interview and not as a result of observation. Since it is not unknown for men to be boastful about their sexual activities, it is possible that in some cases aspirations outreached actual achievement. It seems pretty clear, however, that, in America at least, the ostensible moral code is generally disregarded. And, if the position in Britain differs from that in the United States, the difference is almost certainly one of degree only, since, as has already been mentioned, half of a group of English working men interviewed admitted pre-marital sexual intercourse (Woodside, 1946). The most challenging finding of the American enquiry is that in the men concerned the sex urge appears to have been so powerful during youthit gradually fades from late adolescence onwardsthat it was impossible for the great majority of them to control it, despite all the pressure brought to bear by the moral code of their civilization. Apparently their sex drive had to have some outlet. It would be unrealistic, therefore, to ignore the fact that, in considering the problem of promiscuity or venereal disease, we are dealing with a biological force that is an essential part of man's make-up, and which, although it declines in force as a man ages, is constantly striving to find some form of physical expression during that period of life when its normal outlet in marriage is generally blocked. Despite this, however, the great majority of people escape venereal infection. In what way do those who remain uninfected differ from those who sooner or later reach our clinics?

\section{Promiscuity and Venereal Disease}

There are many investigations that show the relationship between promiscuity and venereal disease. On Tyneside, at least two out of five male infections were attributed to promiscuous women (Macfarlane, 1948). In a group of venereally diseased patients studied in the British Army it was found in round figures that one in three was habitually promiscuous, one in three occasionally promiscuous before joining the army, and one in three occasionally promiscuous since joining the army. When the venereal disease group was compared with controls who had not contracted venereal disease, the numbers habitually promiscuous were found to be six times greater in the diseased group, and the number occasionally promiscuous twice as great (Wittkower, 1948). In the American Army a 
comparison between a group of venereally diseased patients and an appropriate control group showed that eleven of the controls to one of the diseased rarely or never had extra-marital relations (Brody, 1948).

Of venereally diseased patients referred to the San Francisco Psychiatric Service between 1941 and 1944, seven out of ten were promiscuous and two out of ten were assessed as potentially promiscuous. Four out of five of the promiscuous and three out of four of the potentially promiscuousthat is, more than three-quarters of all-were infected with venereal disease. Some of the others had previously been infected but were not found to have a venereal disease at the time of registration (Lyon and others, 1945).

There are many investigations that show the dominating importance of the casual acquaintance or friend as a source of venereal disease. Men who will not consort with a prostitute often willingly expose themselves without precaution to a girl friend if she has resisted their advances for several weeks (Ratcliffe, 1947). Presumably they imagine that having passed such a test she must have withstood indefinitely the overtures of all their predecessors. In Lancashire it was found that threequarters of eighty-one male patients had been infected by casual acquaintances, and it was concluded that promiscuity was the main source of infection (Fessler, 1946). In one study of venereal disease in the British Army it was found that the source of infection was a "pick-up " in three-quarters, and a woman friend in one-fifth of the cases (Wittkower, 1948).

In America, the source of infection was unpaid in two out of three cases in an army camp in Tennessee (Hesbacher, 1943); it was a " pick-up" or friend in over three-quarters of the cases in white soldiers of the United States Army Third Service Command from January to June 1943 (Norris and others, 1943), and in four out of five cases in the American Air Force (Holmes and Chesney, 1945). In these last two investigations venereal disease was bought in only one out of seven and one out of eight cases respectively. And although it appears that two-thirds of the American male population ultimately have intercourse with prostitutes, it is estimated that only one-tenth of the total nonmarital contacts are with prostitutes (Kinsey and others, 1948). About one out of every five promiscuous or potentially promiscuous San Francisco women who admitted voluntary pre-marital relations reported that she had become either pregnant or infected with venereal disease as a result of her first experience, which was usually with a boy friend or fiancé (Lyon and others, 1945).
In San Francisco, two-thirds of promiscuous women and three-quarters of promiscuous men investigated were classified as habitually promiscuous (U.S. Public Health Service Report, 1949). Of every ten promiscuous white San Francisco women, three had had intercourse with four or more men, and one had had intercourse with eight or more men. Approximately one in ten reported intercourse four times a week or oftener during the previous six months ; one in four, one to three times a week ; two in five, one to four times a month; and one in four less than once a month (Lyon and others, 1945).

Altogether these figures underline the great risk of sexual intercourse with a person who is habitually or even occasionally promiscuous. The most striking figure of all is that four out of five promiscuous San Francisco women actually had venereal disease at the time they were discovered to be promiscuous-not over a period of time but at a given moment (Lyon and others, 1945).

\section{Characteristics of the Promiscuous Person}

It is clear that promiscuity is the fundamental problem that we face in examining the individual and social factors in venereal disease. In collating the observations that I have obtained from a number of sources, I propose to put together findings concerning promiscuity and venerea disease.

Age.-In a study of two hundred men and women suffering from venereal disease in Lancashire it was found that almost half were between 21 and 30 years of age (Fessler, 1946); and on Tyneside the peak age for venereal disease was 18 to 24 in women and 25 to 30 in men (Macfarlane, 1948). The findings in the United States were similar. The modal age group for venereal disease contacts in the United States Army Third Service Command was 20 to 24 (Norris and others, 1943); and in New York City from 1940 to 1943 it was found that the largest number of cases was in the 20 to 24 years age group (Rosenthal and Kerchner, 1944). A study of venereally diseased patients and soldiers in one military district in Canada, compared with a control group selected at random from personnel files, showed that the number of men under 22 in the control group was 15 per cent. more than in the group with venereal disease ; that is, venereal disease was more likely to be acquired between the ages of 22 and 30 than under 22 (Watts and Wilson, 1945).

Investigations both in this country and in the United States suggest that the median age of infection is about four years less in females than in 
males (Macfarlane, 1948 ; Rosenthal and Kerchner, 1944); more than half of 861 females suffering from venereal disease in Detroit and interviewed in 1944 were 21 or under (Rolison, 1946); and in Philadelphia about one-fifth of the syphilis and gonorrhœa cases detected were under 20 years of age (Ingraham and Burke, 1945). It appears, therefore, that, if venereal disease is to be contracted, more often than not infection will take place before the ages of 25 in females and 30 in males. This is no doubt related to the fact that, in this country, the average age at marriage is 25 for a spinster and $27 \frac{1}{2}$ for a bachelor.

Sex.-The official figures of the Ministry of Health consistently show the greater incidence of both syphilis and gonorrhœa in males than in females (Report of Ministry of Health, 1947). There is little doubt, however, that more infected women than men are unaware that they have contracted venereal disease, and it is possible that even when they have reason to suspect that they are infected they are more loth to seek advice and treatment. This is strikingly borne out by the figures for cases dealt with for the first time at any clinic during 1946, which show that whereas the ratio of gonorrhœa to syphilis in the male is $2 \cdot 6: 1$, in the female it is roughly $1: 1$. It is therefore probable that the promiscuous female is a greater source of danger than the promiscuous male.

Intelligence.-Although few were mentally defective, the majority of promiscuous women on Tyneside had an intelligence quotient between 75 and 90 (Macfarlane, 1948). In South East Asia Command, infection with venereal disease " correlated to some degree with the distribution of general intelligence" (Ratcliffe, 1947). In a series of venereally diseased patients studied in the Canadian Army, one in five was mentally dull (Watts and Wilson, 1945). In San Francisco the median intelligence quotient of 283 promiscuous or potentially promiscuous white women was 95 . It should be noted, however, that only one out of every ten had an intelligence quotient of less than 80 (Lyon and others, 1945).

An assessment of the intelligence of 394 white women who appeared before the San Francisco Separate Women's Court in 1944 (prostitutes, promiscuous women, alcoholics, drug addicts) showed that only one in three fell within the limits of the normal mental level (I.Q. 91.110), compared with half of the normal population. The incidence of border-line defectives was one-fifth greater than the normal expectancy ; and one out of every three of the total was below defective and border-line defective level (Koch and Wilbur, 1944).
There is some suggestion, however, that the mental level may on the whole be lower amongst those who contract venereal disease than amongst those who are merely promiscuous. In Philadelphia, for example, about one in three of the children under 18 found infected with venereal disease were attending special schools for the retarded (Ingraham and Burke, 1948); and the median intelligence quotient of 304 unselected venereally infected women attending the Rapid Treatment Centre at St. Louis was 75 when tested by the Stanford Binet Form, and 80 when tested by the Otis test, that is, their average mental age was 11 or 12 years. It was concluded, therefore, that they were in the main intellectually inferior individuals (Rachlin, 1944). On the other hand an investigation of the white women appearing before the Separate Women's Court in San Francisco, to which reference has already been made, showed that the percentage of venereal infection was broadly the same for all mental levels (Koch and Wilbur, 1944).

We must conclude, therefore, that, although the evidence is not strikingly conclusive, promiscuity and venereal disease are often related in some degree to lower than average intelligence.

Education.-It appears that with increased education there is a diminished risk of venereal disease. This is probably related in part to greater socioeconomic stability (to which reference will be made later), in part to higher intelligence (already discussed), and in part to less opportunity because of the competing demands of more intellectual activities. There is, too, the pressure of the differing group standards. In the college class of America, for example, masturbation and petting are reported to be considered natural expressions of the sex drive and a reasonable substitute for full sexual relations. In the elementary school class, however, it is generally held that the sensible thing is to have full sexual relations, pre-marital, marital, or extramarital. Consequently masturbation is twice as frequent in the college class as in the elementary school class, while pre-marital intercourse is only one-seventh as frequent. While 98 per cent. of males whose education has carried them no further than the grade school have had pre-marital intercourse at some time, only four out of every five who have gone to high school, and only two out of three of those who have gone to college have had this experience (Kinsey and others, 1948).

In Philadelphia, while the rate of venereal disease amongst elementary and junior high school children (that is up to the age of 14) was roughly the same as in the community as a whole, the incidence amongst senior high school children (aged 15 to 17) was only 
half that of the incidence of the general population (Ingraham and Burke, 1948). In the American forces in Italy during the war, soldiers with relatively little education appeared to be more likely to contract venereal disease (Brody, 1948).

The women undergoing rapid treatment in St. Louis, however, had had, as a group, better than average education, but their median intelligence quotient was only 80 (Rachlin, 1944). This suggests that the important protecting effect of high school or college education rests not in itself, but in the higher intelligence and higher standards that tend to be associated with it.

This inference is supported by the conclusions reached in San Francisco, that although limited formal education and lack of vocational training were frequently associated with promiscuity, they were not causative factors (Lyon and others, 1945).

Religion.-Although they had all had some religious training in childhood, nine out of ten promiscuous women on Tyneside are reported as being no longer interested in religion. Almost all promiscuous or potentially promiscuous women investigated in San Francisco between 1943 and 1944 had been affiliated to some religious group in their childhood; but the majority had ceased attendance at Sunday school or at church before or during adolescence and at the time of the investigation did not adhere to any form of organized religion (Lyon and others, 1945). Three-quarters of the women appearing before the San Francisco Separate Women's Court were religiously inactive (Koch and Wilbur, 1944).

To be of any value, however, these figures must be compared with those for controls, and an investigation of two hundred United States service men in hospital for venereal disease in Italy during the war showed that there was no difference in the type of religious affiliation compared with that of the controls (Brody, 1948).

It is relevant, too, to recall that only a minority of the population of Great Britain is actively attached to some form of organized religion.

Marital Status.-More than half of a group of venereally diseased patients investigated in Lancashire were married (Fessler, 1946), and almost half of a group on Tyneside. In another investigation it was found that the difference between the syphilis rates of single and married men was greater than the difference between occupational groups : amongst over half a million men who entered the United States Army between January and June 1943 there was a positive blood test in more white single men than in married men in all occupations and in all ages except under 20 (Usilton and others, 1945).
In the United States Army in Italy during the war, however, the percentage of single men amongst a group of men with venereal disease was only slightly greater than that in a comparable group of controls, $79: 72$ per cent. (Brody, 1948); and a similar comparison between a group of venereally diseased patients and a control group in the Canadian Army showed that the percentage of married and single men was the same in both (Watts and Wilson, 1945).

Just under two-fifths of the promiscuous or potentially promiscuous women in San Francisco were single, and of the remainder more than half were married, but their husbands were absent, or they were separated, divorced, or widowed. Twothirds of the promiscuous group and half of the potentially promiscuous group had been married one or more times; one-seventh had been married two or more times; one-third of the promiscuous patients had been married before the age of 18 (Lyon and others).

The ratio of married to single amongst 304 venereally infected women in St. Louis was roughly two to one. The age at marriage ranged from 12 to 29. Almost two-thirds of the married women had been married by the age of 18 . Of the married women, two-fifths were living with their husband, one in three was separated, one in five was divorced, and one in fifty was widowed. Of those living with their husband, more than half attributed the disease to him (Rachlin, 1944).

It appears therefore that where venereal disease occurs in married persons there has generally been a preceding disturbance of marital relations, whether due to enforced absence because of the demands of occupation or to the exigencies of war ; a new disturbing factor, as in the case of pregnancy; or incompatibility of every degree from temporary unhappiness to permanent separation or divorce.

Macfarlane considers that incompatibility is the most frequent and important cause of venereal disease in married people. In the Canadian Army it was found that in a group of venereally diseased patients marital incompatibility was present three times more frequently than in the control group. These figures must be related to the finding that of marriages in this country less than half are really happy, and one in five is disastrous or seriously unsatisfactory (Slater, 1947).

Socio-Economic Status.-From an analysis of serological tests in more than half a million selected service registrants in the United States in 1943, it was concluded that "the prevalence of syphilis varies with socio-economic status". The rate was lower in the more highly trained occupations and 
rose steadily as one went down the socio-economic ladder to the unskilled occupations (Usilton and others, 1945).

Two-thirds of a group of 149 cases of women infected with venereal disease were known to one or more social agencies because of previous application for financial or medical assistance; that is, they belonged to an under-privileged group (Rachlin, 1944).

In a San Francisco war industry it was found that the incidence of syphilis decreased with improved socio-economic status: the incidence of positive blood tests amongst unskilled labourers was four and a half times greater than amongst professional workers. In the same industry a distinction was found between entrants who were already employed and those who were unemployed, there being a positive blood test in only 3.7 per cent. of those employed compared with 5 per cent. of those unemployed (Koch and Wilbur, 1944). A San Francisco investigation of promiscuous and potentially promiscuous women showed that the majority came from families with marginal incomes. The investigators concluded, however, that economic deprivations during childhood had been at most a remote contributing factor (Lyon and others, 1945).

Amongst British troops in S.E.A.C. after the war there was a significant predominance of unskilled employment amongst those suffering from venereal disease, and Ratcliffe (1947) found that " the prolonged unemployment of troops or their employment in apparently pointless tasks affects the venereal disease incidence rate as it does morale".

On Tyneside, however, 70 per cent. of all male venereally diseased patients were skilled workers; and Ratcliffe himself concluded that discrepancy between capabilities and type of employment did not appear to be an important factor. Moreover in the United States Army in Italy during the war there appeared to be no difference in the civilian occupations, nor in the regularity of employment in civilian life, between those suffering from venereal disease and a control group; and there was as large a group of non-commissioned officers in a group with venereal disease as amongst the controls (Brody, 1948).

The evidence concerning the influence of socioeconomic status and the nature of employment is, therefore, rather conflicting. The American investigations referred to, however, show striking evidences of such a relationship. If it does exist it is probably due to a complex of factors: the natural tendency of the more intelligent and more self-disciplined individuals to ascend the socioeconomic scale; the greater range of satisfying activities open to those who are better off ; and the discouraging effects of an unsatisfactory environment and frustrated ambitions and aspirations.

Residence.-There is little doubt that the movement of the population from its place of permanent residence tends to increase the incidence of venereal disease.

In a war industry in California the blood test was positive in only 3.8 per cent. of new employees who were already resident in the district, compared with 6.3 per cent. of transients (Koch and Wilbur, 1948). And as a result of a study of the factors that were tending to shift the incidence of venereal disease towards the teen-ages in the United States between 1914 and 1944, it was concluded that " the exposure rate rises with the removal of young girls from their homes and from school to overcrowded areas without adequate housing, recreation, and other normal living conditions" (Heller, 1946).

Approximately two-thirds of 283 promiscuous San Francisco women "were living alone, or with friends, usually in third- or fourth-rate hotels" (Lyon and others, 1945).

It seems, therefore, that separation of the individual from his natural neighbourhood unit reduces the restraint that group pressure exercises upon his behaviour in the sexual field, as no doubt in other matters. As well as this, of course, he is deprived of the social activities from which he has formerly derived satisfaction and security, and there is a break in his established human relations. There is, therefore, an urgent need to establish new and intimate associations : relations based on sex offer an easy, quick, and exciting way of doing so.

Family Background.-On Tyneside it was found that the great majority of promiscuous women " came from broken homes where parents were separated or did not agree, or where parents were over-strict with the women when they were younger" (Macfarlane, 1948).

An investigation of promiscuous or potentially promiscuous women in San Francisco showed that the parents of three out of every five were separated, divorced, or dead. In the majority of the broken homes the parents had re-married one or more times, and the psychological effects of stepfathers, stepmothers, or stepbrothers or sisters were noticeable. Inconsistencies in training and discipline had commonly been experienced, and there had often been divided loyalties between incompatible parents. Altogether, it appeared that four out of every five had unresolved conflicts concerning their families (Lyon and others, 1945). Almost three out of every five of 1,402 women appearing before the San 
Francisco Separate Women's Court came from broken homes (Koch and Wilbur, 1944).

In a study of the social background of 249 venereally infected women in St. Louis, it was found that half came from broken homes and two-thirds of the remainder from homes where conflict was reported. Only one in six of the women studied came from homes without conflict, and all of these were married ; half of them attributed their infection to their husbands and the remainder indicated marital difficulties. In this investigation, therefore, all those in the unmarried group came from broken homes or homes where there was a conflict between the parents (Rachlin, 1944).

A study of the family history of 292 venereally diseased patients in a Canadian Army unit showed a history of abnormal childhood twice as often as in a group of undiseased controls (Watts and Wilson, 1945). It is clear, therefore, that promiscuity and venereal disease are often associated with an unsatisfactory family background. Here again the persons concerned are apparently seeking outlets for basic human needs that have been thwarted during childhood or that are unsatisfied in marriage.

Personality.-In South East Asia Command a history of delinquency, poor work record, and inability to settle in the service, occurred four times more frequently amongst the British troops with venereal disease than amongst the control group. The number of men with a history of past social maladjustment was, therefore, significantly higher in the venereal disease group. Indeed, officers with venereal disease were almost invariably socially maladjusted or inadequate personalities with a poor service record. Ward disciplinary problems also occurred more frequently amongst the venereally diseased patients (Ratcliffe, 1947).

Among 292 venereally diseased patients in the Canadian Army previous reference to a psychiatrist had occurred eight times more frequently than among the controls, poor military efficiency twice, dissatisfaction with the army placement three times, and poor conduct four times as frequently. Of those with venereal disease who had been referred to a psychiatrist, nineteen out of twenty were emotionally or intellectually handicapped (Watts and Wilson, 1945).

A study in the British Army showed that emotional immaturity occurred three times more frequently in venereally diseased patients than in controls and that in the infected group there was only one mature personality for every six in the control group. One out of five male venereal disease patients had been judged on moderate or serious charges (Wittkower, 1948).
In the United States Army in Italy during the war it was found that a higher percentage of venereally infected patients had records of repeated arrests in civil life or of punishment in the army than was the case in a control group (Brody, 1948).

Of 365 promiscuous or potentially promiscuous San Francisco women one out of eight was known to have been through the juvenile courts, one in seven through the adult courts, one in six in a correctional school or gaol (Lyon and others, 1945).

The association between delinquency and venereal disease is particularly striking in adolescence. In Philadelphia, venereal disease was found to occur four times more frequently in delinquent children under the age of 18 than in Senior High School children of the same age group. The venereal disease rate in delinquent children was actually greater than in the whole adult population, and there was a significant change in the sex ratio : in the normal population under 18 years of age, four females were infected to every three males; in delinquent children under the age of 16 the ratio was ten females to every one male; and, in the 16- to 17-year-old group five and a half females to every one male. Almost one out of every four delinquent girls aged 16 to 17 had venereal disease. There was, too, a striking alteration in the racial ratio of venereal disease amongst non-whites compared with whites. In the total population the ratio was 20 to 1 . Amongst delinquent children under the age of 16 it was reduced to 4 to 1 and for the ages of 16 to 17 to 2 to 1 . It was therefore concluded that a positive correlation between venereal disease and juvenile delinquency was indisputable (Ingraham and Burke, 1945).

On Tyneside, it was found that one in five of all promiscuous persons was irresponsible, often defaulting, and easily influenced. And at the Rapid Treatment Centre at St. Louis, it was found that whatever their earnings, venereally infected women squandered them without any regard for the future (Rachlin, 1944).

Amongst the personality characteristics common to many of the promiscuous or potentially promiscuous San Francisco women were uneven development of different panels of the personality, the assumption of self-direction in advance of emotional maturity, minimal group associations before leaving home, limited discrimination in the selection of friends and employment, unwillingness to accept responsibility for their own behaviour, blaming others for their own shortcomings, and ambivalence between dependence and independence. Incidentally, one out of every three of these women had had illegitimate pregnancies (Lyon and others, 1945). These findings are confirmed in a later report 
where it is stated that "promiscuity appeared in most cases to be symptomatic behaviour arising out of neurotic conflict. Current environmental factors were often found to have contributed to the promiscuous behaviour but could not be considered as the primary cause in any case of habitual promiscuity." It was concluded that, with few exceptions, promiscuity was the result of difficulties within the personality (U.S. Public Health Service Report, 1949).

A striking indication of the personality differences between those who contract venereal disease and those who escape is the finding in the United States Army in Italy during the war that the average age of the first heterosexual experience in a group with venereal disease was 16 years compared with 16 years and 7 months in the control group (Brody, 1948). It seems that the ability to wait those extra seven months carries with it a lasting capacity to withstand temptation, or at any rate, a greater degree of control that ensures more fastidious selection of partner and greater care in the act.

In the case of the white women undergoing treatment in the Rapid Treatment Centre in St. Louis, the median age was actually between 15 and 16. Of the married women with venereal disease roughly half had had their first sexual experience prior to marriage (Rachlin, 1944). This is double the number reported in a representative group of English working-class married women (Woodside, 1946).

These findings establish beyond question that the reaction to the temptations of sex tends, as one would expect, to be characteristic of the individual's whole approach to life. By the time he reaches adolescence he has established a pattern of behaviour which tends to be self-controlled, considerate, farseeing, and ethically sound, or the reverse. This fact is stressed by Draper (1946), who considers that there are three categories of people : those who will in no circumstances expose themselves to the risk of infection; those who will expose themselves and acquire venereal disease without thought; and those whose conduct and chances of acquiring venereal disease depend upon general environment, opportunity, and current emotional adjustment and morale.

It is necessary to add, however, that there is a wide range in the strength of the initial drives, and in the innate power of self-control. Moreover, a combination of exceptional circumstances may break down the control of an individual who would ordinarily escape the risk of venereal disease.

Alcohol.-It is generally accepted that there is a relationship between alcohol consumption and promiscuity. In South East Asia Command, although real drunkenness was comparatively rare, the consumption of alcohol often led to venereal disease. Its effects were to produce increased desire, a weakening of restraint, and failure to take precautions during or after intercourse (Ratcliffe, 1947). On Tyneside alcoholic indulgence in varying degree was admitted in four out of five cases. The influence of alcohol was particularly marked where there was sexual incompatibility in marriage (Macfarlane, 1948). Amongst white United States troops in Italy who contracted venereal disease during the war, there were more than four heavy drinkers for every one in a control group (Brody, 1948) ; in the Canadian Army drunkenness occurred in venereal disease nineteen times more frequently than amongst the controls (Watts and Wilson, 1945); and in the British Army there were fifteen heavy drinkers amongst the venereally diseased patients for every one in a control group (Wittkower, 1948). Viewing the problem from another angle, Bird (1949) states that in alcoholism the most constant finding is immature and unsatisfactory sex behaviour.

It is not clear, however, whether venereal disease is a consequence of alcoholism, or whether both alcoholism and promiscuity are expressions of some basic emotional instability or personality defect or frustration.

Meeting Place.-The infected consorts of the venereal disease cases in the British Army studied were picked up mostly in public houses, and then in the street, in dance halls, cinemas, and fun fairs, in that order of frequency (Wittkower, 1948). This is confirmed by Macfarlane (1948), who found that the public house was the meeting place in three out of five cases. From his investigation it appears also that, so far as venereal disease is concerned, dance halls are safer places than railway stations or the street. It should be remembered; however, that more people frequent the streets and railway stations than dance halls; so that the population at risk in the dance halls is very much smaller.

In the cases investigated in a Tennessee army camp in 1941-42, an hotel, café, restaurant, or "honky-tonk" was the meeting place in two out of five cases, the street in a quarter of the cases, and a dance hall; skating rink, or theatre in only one out of every twenty cases (Hesbacher, 1943).

In the United States Army Third Service Group in 1943, a tavern was the leading place of encounter (Norris and others, 1943); and it appears that about three out of five of all venereal disease cases in San Francisco are contracted through meetings 
in bars and taverns (Koch and Wilbur, 1944).

There seems, therefore, to be a clear relationship between licensed premises and venereal disease, and it might be of interest to attempt to relate the incidence of venereal disease in different towns with the ratio of licensed premises to inhabitants, which in Newcastle, is one to 45. It would be difficult to decide, however, whether a high ratio of licensed premises was the cause of a high incidence of venereal disease, or whether both were merely joint consequences of more basic unsatisfactory social conditions.

Effects of War.-During the war there was some evidence in the United States of a shift in venereal disease infection towards the teen-ages. In New York City, for example, between the years 1940 and 1943 there was a lowering of the median age for syphilis in both males and females and for gonorrhœea in males; but after a preliminary fall the median age of females suffering from gonorrhoea returned to approximately the 1940 rate (Rosenthal and Kerchner, 1944).

An examination of figures for the whole of the United States showed, however, that this lowering of the median age had been neither nation-wide nor consistent from one year to another. Indeed, the shift took place in only a minority of states (Heller, 1946).

In Philadelphia, while it is true that the number of cases of venereal disease in the 5 to 17 age group increased from 744 cases in 1945 to 801 in 1946 and to 1,269 in 1947, when the incidence was related to the total incidence of venereal disease in the whole population (which had also increased) it was found that venereal disease in the under $18 \mathrm{~s}$ had actually decreased from 8.4 per cent. of the total cases in 1945 to 5.7 per cent. in 1946, with an increase again to 7.4 per cent. in 1947, which was, however, relatively less than in 1945 (Ingraham and Burke, 1948). So far as the United States is concerned, therefore, it appears that in general the younger age groups merely shared in an increased incidence of venereal disease during the war.

Reasons for Promiscuity.-Ratcliffe (1947) considers that the motives leading to promiscuity are generally multiple and mixed. The most common reasons given were that the man just wanted to have sexual intercourse and that in any case it was the obvious thing to do. Amongst more immature or inadequate men, however, there was often advanced the excuse that he had been led on by other men, or that his wife had been unfaithful, or that he wanted to prove his manhood. Ratcliffe considers that the two main periods of increased risk were the homesick phase that followed drafting overseas, and the period after three years overseas. $\mathrm{He}$ believes that the factors which lower morale inevitably increase the venereal disease rate and that it is " no coincidence that a unit with a low sick rate, an empty guard room, and few cases of venereal disease has also high morale".

From a San Francisco study it appeared that the reasons for promiscuity included search for affection, revenge on a husband for his unfaithfulness, concern because no orgasm was experienced with the original partner, desire to be one of the gang, curiosity and experimentation, search for enjoyment (that is, the partner was merely an accessory to personal physical gratification), an attempt to overcome frustration, an attempt to solve conflicts concerning repressed sexual urges, defiance of authority. The search for pleasure cannot, however, be the dominating reason for promiscuity, since the reactions to sexual intercourse were reported as pleasant in only two out of five cases, and as indifferent or unpleasant in one out of four. Single promiscuous girls enjoyed intercourse less frequently than those who were married. It was significant, too, that those women whose reactions to sexual intercourse were pleasant were less inclined to change their partners frequently than were the others (Lyon and others, 1944).

Reactions to Infection.-Ratcliffe reports that the characteristic attitude is one of apathy or bravado. One-seventh of the cases studied by Wittkower had been infected previously. This suggests that in many cases infection does not have any markedly deterrent effect. Nevertheless, there is little doubt that venereal disease often causes serious emotional disturbance. Amongst the promiscuous San Francisco women who were studied psychologically, there was found a feeling that they would never be clean again; concern lest parents or relatives should learn that they were infected; fear that they would be recognized at the clinic or found out by employers, friends, or husband ; fear of becoming sterile; a feeling that they had let themselves down ; and the conviction that they were being supernaturally punished for promiscuous behaviour (Lyon and others, 1944).

Since the Ministry of Health and the Central Council for Health Education began the national campaign against venereal disease in July 1942, over 130,000 letters have been received from members of the public asking for information concerning venereal disease or sex. From a study of these it is clear that patients infected with venereal disease often feel permanently polluted and fear that they will be sterile, or that if they later conceive the baby may be inferior. (This last fear is something apart 
from the fear of congenital syphilis.) Even where patients have been reassured perhaps more than once by clinic doctors or others that they are free from venereal disease they often remain convinced that they are infected. No doubt this is sometimes due to a phobia, but I suspect that in many cases there is a non-specific infection which has been disregarded by the clinician, who has failed to find evidence of the presence of the gonococcus or the spirochæte. In these cases, although physical signs of infection may be absent or undetected, symptoms remain and may cause much mental anguish and even disrupt the marital relationship. It appears that many of those people have a natural fear of passing on to their mate the infection from which they believe themselves, rightly or wrongly, to be suffering. In any case, many of them apparently become uninterested in sexual intercourse and some become impotent. Apart altogether, therefore, from the effects upon their own mental health, the consequences for their married relationship are obviously often very serious indeed.

Motivation for Going to Clinic.-In the United States roughly two-thirds of the patients suffering from untreated primary or secondary syphilis attending the venereal disease clinics between July 1946 and December 1947 came on their own initiative and about one quarter as a result of contact investigation (Editorial, J. vener. Dis. Inf., 1948).

In a Lancashire study it was found that of the patients attending a venereal disease clinic 57 per cent. of the males compared with only 13 per cent. of the females came of their own accord, that is, the male to female ratio of spontaneous attendance was 4 to 1 . Approximately 40 per cent. of both males and females had been sent by their doctor, so that only 4 per cent. of the males had to be persuaded by other means compared with almost 50 per cent. of the females; that is, relatively twelve times more females than males had to be persuaded to attend the clinic (Fessler, 1946). These facts are no doubt related to the finding that more than one-third of 266 servicewomen admitted to a military hospital between June 1942 and January 1945 and proved to have gonorrhœa, regarded themselves as symptomless and only came under treatment accidentally or because they were reported as sources of infection (King and Gallagher, 1946).

Clearly, therefore, women who are themselves unaware that they are infected are especially dangerous potential sources of infection. Having no reason to suspect that there is anything wrong with them, they are unlikely to be led to seek advice by ordinary education concerning venereal disease. A special approach must, therefore, be made to them. A really intensive, efficient, and determined method of contact-tracing is the most likely means of bringing in these hidden cases. Indeed it would seem that a thorough attempt to trace and to treat all contacts, near and remote, with the patient actually presenting himself at the clinic, will do more than anything else to reduce the incidence of venereal disease.

Regularity of Attendance.-In Lancashire married women apparently attend more regularly than single factory girls. This is especially the case where the married women have been infected by their husbands (Fessler, 1946).

Macfarlane considers that the reasons for defaulting are irresponsibility, domestic trouble, fear of the doctor, fear of being seen, fear of waiting-room gossip. The woman with a young family is a special problem, because it is so difficult for her to find a convincing reason for leaving her young children with other people at regular intervals.

Case holding is therefore as important as case finding. More rapid methods of treatment, better administration, better amenities, and adequate and sympathetic discussion with the patients can all contribute to this end. The case holding value of rapid methods is strikingly brought out by the finding that in American clinics (July to December 1944) three times more patients (92 per cent. compared with 30 per cent.) completed treatment under in-patient rapid treatment methods than when routine treatment was given (Heller, 1945).

Rehabilitation.--Since venereal disease is so frequently the outcome of promiscuity, and, as has been shown, promiscuity itself often has its roots in personality weaknesses or maladjustments, it is clear that unless something is done to re-educate or re-habilitate a venereal disease patient, it is very likely that upon his return to the community he will revert to his former way of life, become re-infected, and in due course return for treatment. In an investigation already referred to, for example, one out of seven of the venereally diseased patients had been previously infected (Ratcliffe, 1947).

It is obvious, therefore, that in treating venereal disease, the whole patient must be treated and not merely his infected reproductive tract. "A programme restricted entirely to the treatment of patients without bringing to the attention of appropriate agencies the need for some form of rehabilitation for certain patients would be ineffectual" (Rachlin, 1944). And "although penicillin has a striking effect upon the gonococcus and a 
considerable influence upon the spirochæte pallida, it does not affect the behaviour habits which led to exposure to the risk of contracting venereal disease " (Watts and Wilson, 1945). Indeed, many experienced clinicians consider that the speed and the relative simplicity of modern treatment may reduce the existing fear of venereal disease and therefore actually encourage promiscuity where a tendency towards it already exists.

The experiments in the rehabilitation of promiscuous women carried out in San Francisco are therefore of special interest. Of those who had been treated by psychiatric methods and who had been followed up six months after rehabilitation treatment, one half had ceased sexual contacts except within marriage (Lyon and others, 1945), and in a later report it is shown that of the patients of both sexes for whom a follow-up was possible, nine out of ten had reduced their promiscuity, or had not become promiscuous although they had been considered potentially promiscuous ; and of these again half had had no sexual contacts except in marriage. It is therefore concluded that psychiatric facilities in association with a venereal disease clinic are worth while. There appears to be an important relationship between intelligence and susceptibility to rehabilitation, however, since the use of this rehabilitation service increased with intelligence, there being a significant increase at the intelligence quotient level of 80 in the case of the women and at that of 90 in the case of the men.

In this connexion it is encouraging to note that although one-third of the white women appearing before the San Francisco Separate Women's Court in 1944 were below defective or borderline defective level, two-thirds were above that level, and therefore intellectually capable of responding to re-directional care (Koch and Wilbur, 1944). It seems, therefore, that time and money given to attempts at rehabilitation will be well spent.

Sex Education.-Few of the 365 promiscuous or potentially promiscuous San Francisco women investigated "felt that they had received adequate sexual information from their parents or from others responsible for their training", and many felt that their parents had been too strict and repressive in their attitude towards companionship with boys and men (Lyon and others, 1945).

The relationship between venereal disease and ignorance concerning sexual matters is also brought out by the finding (Brody, 1948) that three times as many of the men with venereal disease as of the controls thought that sexual intercourse was necessary for health (36 per cent. compared with 12 per cent.), while the ratio of those who considered masturbation injurious was 4 to 3 (74 per cent. compared with 55 per cent.).

Sex education is of course of very great importance quite apart from its possible value in the attack on the venereal diseases. So far as the venereal diseases are concerned, however, we must continue and extend our efforts to have the disease recognized as an ordinary infectious disease, spread by contact, in this case contact of special parts of the body-the sexual organs. All members of the public should know something about the means by which various infectious diseases are spread and by which their spread can be prevented. Knowledge of the relevant facts concerning venereal disease should be an integral part of this wider study. Our aim should be to spread knowledge of the real nature and sources of venereal infections; to discourage exposure to infection; to encourage early and continued treatment of proved disease; and to decrease the unwitting transmission of infection.

\section{Conclusion}

There is, of course, no such thing as an average venereal disease patient. He is a statistical artefact. But a study of the observations that I have collated suggests that there are certain individual and social factors that tend to be associated with promiscuity and venereal disease. It is important to social medicine that we should increase our knowledge of these factors because, when their influence is established and recognized, we may be able to do something that will modify their effects and thus indirectly contribute to our attack on the venereal diseases. Their study is equally important in each individual case, however, since, if they have played a part in causing the infection that has brought the patient to our notice, it is likely that they will continue to act upon him and perhaps lead to a second infection.

I venture to suggest, therefore, that in the treatment of venereal disease the whole patient must be studied and treated as well as his infected tissues. In the first place, venereal disease has so many individual, marital, and social implications that every patient is anxious and disturbed. He can be greatly helped if a real effort is made to discover and allay his hidden fears and anxieties and to smooth the difficulties and complications that seem to be overwhelming him. In short, he must be treated as a disturbed personality as well as a diseased body.

There is, however, another equally important aspect of the social-medicine approach to the treatment of venereal disease. Although there are many people who have the misfortune to acquire venereal disease by the first promiscuous act (if a first act can be called promiscuous), the evidence 
that I have collated suggests that in the majority of cases the behaviour that led to infection was an expression of serious disturbance within the individual or between him and the civilization in which he lives, the conventions and the moral codes that society demands that he should serve. In this light, the venereal disease itself is a symptom rather than a closed entity-an expression of internal or external emotional maladjustment and disharmony. It is true that with modern methods of treatment the great majority of patients can be cured of their venereal disease. Unless, however, we probe to find out what are the factors within them or in their environment that have brought them to this pass ; and unless, having found these factors, we directly or through other agencies help them to overcome the external difficulties and to modify their reaction to them, we are merely sending back into sexual circulation someone who is fundamentally unchanged and who is likely to expose himself and others to infection again. In short, we have only temporarily broken the chain of infection. The results of the San Francisco attempts at rehabilitation suggest that there is here a field that we might with advantage develop in this country.

Venereal disease is in many cases a symptom of promiscuous habits which, in a society that ostensibly puts sexual morality so high in its moral code, suggests that there are internal or external contributing factors in some degree peculiar to the individual concerned. We must, therefore, increase our study and extend our knowledge of these individual and social factors that lie behind the problem of venereal disease and promiscuity. In searching through the literature I have been forced to the opinion that we have not yet in this country to any great degree applied the social-medicine approach to the study of venereal disease. It is to be hoped that the Medical Society for the Study of Venereal Diseases will take the lead in stimulating such an approach to this important problem.

\footnotetext{
REFERENCES

Bird, H. (1949). J. soc. Hyg., 35, 9.
}

Brown, W. G., and Nichols, W. B. (1948). Canad. J. publ. Hlth, 39, 123.

Brody, Morris W. (1948). "Men Who Contract

Venereal Disease." J. vener. Dis. Inf., 29, 234.

Draper, W. F. (1946). J. soc. Hyg., 32, 185.

Editorial. (1948). J. vener. Dis. Inf., 29, 190.

Fessler, A. (1946). British Journal of Venereal Diseases, 22, 21.

Galloway, J. F. (1949). (Personal communication.)

Greve, C. H. (1946). Amer. J. publ. Hlth, 36, 751.

Heller, J. R. Jr. (1946). Ibid., 36, 501.

-(1945). J. vener. Dis. Inf., 26, 168.

Hesbacher, E. N. (1943). Ibid., 24, 189.

Holmes, E. M. Jr., and Chesney, L. (1945). Ibid., 26, 5.

Ingraham, N. R. Jr., and Burke, M. J. (1948). Ibid., 29, 362 .

King, A. J., and Gallagher, E. (1946). Lancet, 1, 916.

Kinsey, A. C., Pomeroy, W. B., and Martin, C. E. (1948). "Sexual Behaviour in the Human Male." London : W. B. Saunders Co.

Koch, R. A., and Wilbur, R. L. (1944). J. soc. Hyg., 30, 517.

Lyon, E. G., Jambor, Helen M., Corrigan, Hazel G., and Bradway, Catherine P. (1945). "An Experiment in the Psychiatric Treatment of Promiscuous Girls." City and County of San Francisco Department of Public Health.

Macfarlane, W. V. (1948). Publ. Hlth Lond., 61, 147.

Norris, E. W., Doyle, A. F., and Iskrant, A. P. (1943). J. vener. Dis. Inf. 24, 283.

Pearl, R. (1939). " The Natural History of Population." London: Oxford University Press.

Rachlin, H. L. (1944). J. vener. Dis. Inf., 25, 265.

Ratcliffe, T. A. (1947). J. R.A.M.C., 89, 122.

Report of the Ministry of Health for the Year 1947. H.M.S.O.

Report on "A Psychiatric Approach to the Treatment of Promiscuity." (1949). U.S. Public Health Service, California State Department of Public Health, and San Francisco Department of Public Health. J. soc. Hyg., 35, 20.

Rolison, Charlotte (1946). Ibid., 32, 18.

Rosenthal, T., and Kerchner, G. (1944). J. vener. Dis. Inf., 25, 361.

Slater, Eliot. (1947). Address at Central Council for Health Education Summer School, Oxford.

Stocks, P. (1944). Monthly Bulletin of Ministry of Health, 3, 55.

Usilton, L. J., Bruyère, P. T., and Bruyere, M. C. (1945). J. vener. Dis. Inf., 26, 216.

Watts, G. O., and Wilson, R. A. (1945). Canad. med. Ass. J., 53, 119.

Wittkower, E. D. (1948). British Journal of Venereal Diseases, 24, 59.

Woodside, Moya (1946). Eugen. Rev., 38, 29. 